\title{
Lecturers' Cultural Sensitivity on Using Social Media - Facebook and
}

\section{Instagram}

\author{
E. Handayani Tyas ${ }^{1}$, Sunarto ${ }^{2}$, Lamhot Naibaho ${ }^{3 *}$, Bernadetha Nadeak ${ }^{4}$, Elferida Sormin 5 \\ ${ }^{1,4}$ Postgraduate Program, Magister of Education Management, Universitas Kristen Indonesia \\ ${ }^{2}$ Faculty of Education and Lecturer Training, Biology Education Department, Universitas Kristen Indonesia \\ ${ }^{3}$ Faculty of Education and Lecturer Training, English Education Department, Universitas Kristen Indonesia \\ ${ }^{5}$ Faculty of Education and Lecturer Training, Chemistry Education Department, Universitas Kristen Indonesia \\ *Co-Author: lamhot.naibaho@uki.ac.id
}

\begin{abstract}
:
This study aims to identify lecturers' cultural sensitivity to using social media - Facebook and Instagram. This study was done at Universitas Kristen Indonesia. The data collection method used in this study is the quantitative method. A total of 345 lecturers were participated in answering the questionnaire. The data of this study were analyzed using SPSS Statistics and descriptive statistical analysis. This study shows that the diverse findings for the sensitivity of cultural diversity based on ethnicity, gender, level of education, the field of teaching, teaching experience, and teaching experience of students of various nationalities and cultures. The findings of this study have implications for educational knowledge and professional practice, especially for lecturers, and the academic community, higher education that offers to teach courses to play a role and take responsibility for the need to provide prospective teachers' candidate to have a high level of cultural diversity sensitivity in line with the reality of student diversity in higher educations today on them using social media - Facebook and Instagram.
\end{abstract}

Keywords:

cultural sensitivity, social media, Facebook, Instagram

Article Received: 18 October 2020, Revised: 3 November 2020, Accepted: 24 December 2020

\section{INTRODUCTION}

Indonesia's national development's critical agenda is to encourage and maintain integration between ethnic and educational institutions playing an essential role in this effort. An "understanding of other ethnic cultures is fundamental, and this understanding can help maintain stability in society" $[1 ; 2]$. In this context, "one of the best ways to achieve understanding and mutual respect is through education" [3]. However, "racial issues that threaten national unity and harmony still occur" [4]. Racism is the main challenge to form harmonious ethnic relations in the country [7]. Racism also exists in education, especially among lecturers who show discrimination towards students of different ethnicities who have been reported by local newspapers. The reality of the 21 st century requires higher education to respond effectively and appropriately to diverse ethnic and cultural groups in higher education and the entire higher education community and prepare students to create positive interactions with culturally diverse individuals [5]. An important pioneer of cultural competence is inter-cultural sensitivity [6].An individual's affective response to intercultural differences is known as intercultural sensitivity [8]. To be "effective in another culture, individuals must be interested in that culture, be sensitive enough to identify cultural differences that exist, and be willing to change behaviour as an indication of respect for other individuals from a culture that different" [9]. An effective lecturer is "a person who is aware, sensitive to the reality of various backgrounds of students and needs in the classroom. Intercultural sensitivity has been conceptualized in two forms, namely: (1) as a significant aspect in intercultural communication competencies, (2) development as a subjective experience of different cultures" $[10 ; 11]$.

Intercultural sensitivity is conceptualized as a critical element of cultural competence, where an increase in intercultural sensitivity leads to an increase in cultural competence [12]. Intercultural sensitivity refers to discriminating and going through relevant experiences of cultural differences [13]. Intercultural sensitivity is defined "as someone who has an active desire to motivate themselves to understand, appreciate and accept cultural differences" [14]. "Individuals with high levels of cultural diversity sensitivity tend to have good intercultural communication" [15]. The need for intercultural sensitivity to be limited to "the affective aspects of intercultural 
competence to show differences from intercultural awareness, cognitive characteristics and intercultural competence and behavioural aspects regarding cultural competence" [16]. Intercultural Sensitivity Inventory (ISS) was designed to measure "intercultural sensitivity using five factors, namely: a) interacting involvement, b) respect for cultural differences, c) interacting confidence, d) the pleasure of interacting, e) the concern of interacting" [17; 18]. Intercultural sensitivity is "also defined as the experience of cultural differences, and those experiences depend on the way an individual forms those differences [19]. DMIS explains how one understands or sees cultural differences" [20]. Intercultural sensitivity also refers to "the ability to see differences and build relevant experiences of cultural differences" [21;22].

High sensitivity to cultural diversity is related to the increased potential for the application of cultural competencies [23]. DMIS by dividing intercultural sensitivity into six levels, namely denial, defence and reduction were belonging to the group of ethnocentrism, while acceptance, adaptation and integration belong to the class of ethno-relativism [24]. Ethnocentrism refers to the field or attitude that believes that one's own ethnic culture is superior to other ethnic cultures [25]. On the other hand, ethnicity refers to the field or attitude that believes that ethnic culture itself is not necessarily superior or absolute, but differs between individuals or cultures [26]. Based on DMIS, individuals who are sensitive to cultural differences have an ethnic-relative orientation, while less sensitive individuals are ethnocentric [27]. Bennett's model covers six stages of moving from denial to acceptance of cultural differences. This model's stages are progressive and linear, where each step moves to a deeper level of cultural sensitivity. DMIS "is based on the belief that one's experience or understanding of cultural differences becomes more complex; hence one's potential for cultural competence is increased" [28]. Based on the literature review conducted, "lecturer education programs are less challenging to the personal perspective of prospective lecturers with different environmental experiences compared to their background" [29]. Exposure to cultural diversity is minimal if lecturer education programs confine experience within institutional boundaries and prospective lecturers' cultural context. Past studies have demonstrated the importance of exposure to a multicultural environment in lecturer education programs $[30 ; 31 ; 32]$.

Based on the importance of exposure to a multicultural environment, this study only involves higher educations consisting of multiethnic students who provide exposure to an environment rich in ethnic and cultural diversity to current lecturers serve $[33 ; 34]$. Studies on the sensitivity of this cultural diversity have been conducted extensively involving education, healthcare, mental health, business and social work. However, the study of the sensitivity of cultural diversity in education in Indonesia is less made the main focus of the study by researchers. Therefore, this study focuses on cultural diversity among lecturers of various ethnicities in national secondary higher educations in Indonesia. Through this study, we can find out whether lecturers in Indonesia have the required sensitivity of diversity or not. This study was conducted to identify the level of cultural diversity sensitivity among multi-ethnic lecturers in the multi-ethnic higher education environment in Indonesia. The sensitivity of cultural diversity among lecturers is determined based on ethnicity, gender, level of education, the field of teaching, teaching experience, teaching experience of students of various races and cultures, and courses or training on cultural diversity that lecturers have attended.

\section{METHODOLOGY}

The method of the research used was a quantitative method with survey design. It was chosen to be the design of this study because it involves a large number of samples. This method is suitable for use due to its high reliability while the cost is low $[35 ; 36]$. This research was done at Universitas Kristen Indonesia within three months from August - November 2019. The instrument of the study was a set of the questionnaire consisted of 24 statements. All of the lecturers (335) from a different cultural background filled up the questionnaire. The purposive sampling method was applied by making all of the lecturers the respondent of this research. The questionnaire of this research was adapted from Chen and Starosta, namely the intercultural sensitivity scale in the preparation of cultural diversity sensitivity questionnaires, and it has been through the 
validity of the content by seven experts who are knowledgeable in the field of ethnic and cultural relations, multicultural education and research. Analysis of the findings of this study using IBM SPSS Statistics 22. The reliability of items to measure a construct is indicated by Cronbach Alpha values 0 to 1.0. The greater the value of an item's coefficient, the higher the degree of reliability of the thing. The result of the reliability coefficient test of the object of cultural diversity sensitivity questionnaire is 0.79 . An alpha value above 0.70 indicates that the questionnaire has good internal reliability.

\section{RESULT AND DISCUSSION}

Descriptive statistics were used to study the level of cultural diversity sensitivity among lecturers based on each characteristic of lecturers involved namely ethnicity, gender, level of education, the field of teaching, teaching experience, teaching experience of multi-ethnic and cultural students as well as cultural diversity courses or training that lecturers have attended. Determination of the level of cultural diversity sensitivity among multiethnic lecturers involved in this study is based on the highest mean for each category of lecturers studied, namely ethnicity, gender, level of education, the field of teaching, teaching experience, teaching experience of multi-ethnic and cultural students and courses or cultural diversity training ever attended by lecturers.

The lecturers who are Bataknese $(\mathrm{M}=2.83$, $\mathrm{SD}=.31$ ) have a level of sensitivity that cultural diversity is higher than the lecturers who were Javaness $(\mathrm{M}=2.82, \mathrm{SD}=27)$ and lecturers who are Non-Batakness and Javanese $(\mathrm{M}=2.74, \mathrm{SD}=$. 29). The results showed that the lecturers of the Batakness have a level of sensitivity that cultural diversity is higher than the lecturers of the Javanese ethnic group and lecturer of NonBataknese and Javanese. Therefore, based on a sample of lecturers of various ethnic groups involved in the study, Batakness lecturer found a sensitivity level of cultural diversity higher than the Javanese lecturers and Non-Bataknese and Javanese lecturers. A lecturer with a "high level of cultural diversity sensitivity, someone who has an active desire to motivate himself to understand, appreciate and accept cultural differences" [37]. Lecturers can "play a role either in strengthening or rejecting cultural diversity" [38; 39]. To be sensitive to cultural diversity must always understand and deal directly with the sensitivity between cultures.

Female lecturers $(\mathrm{M}=2.81, \mathrm{SD}=.29)$ had a higher level of cultural diversity sensitivity compared to Male lecturers $(\mathrm{M}=2.76, \mathrm{SD}=.26)$. Based on gender, female lecturers have a higher level of cultural diversity sensitivity compared to male lecturers. This study's findings are consistent with the study that found that "women have a higher level of intercultural sensitivity than men" [40; 41].

Lecturers with the highest level of education are doctoral $(\mathrm{M}=3.09, \mathrm{SD}=.31)$ have a higher level of cultural diversity sensitivity compared to lecturers with Certificate $(\mathrm{M}=2.83, \mathrm{SD}=.24)$, Master $(\mathrm{M}=2.89, \mathrm{SD}=.33)$, Degree $(\mathrm{M}=2.78$, $\mathrm{SD}=.31)$ and Diploma $(\mathrm{M}=2.78, \mathrm{SD}=.25)$. Based on the highest level of education, lecturers with the highest education level, namely $\mathrm{PhD}$, have a higher level of cultural diversity sensitivity than lecturers with Certificates, Masters, Degrees and Diplomas. The study's findings also show that lecturers who only have a Certificate qualification have the second-highest level of cultural diversity sensitivity. This study's findings are inconsistent with the study, which found that "the higher the level of lecturer education is strongly related to the level of intercultural sensitivity among lecturers" [42].

Science lecturers $(\mathrm{M}=2.783, \mathrm{SD}=.32)$ have a higher level of cultural diversity sensitivity than Literature lecturers $(\mathrm{M}=2.886, \mathrm{SD}=.28)$. Science lecturers have a higher level of cultural diversity sensitivity than Literature lecturers based on the teaching field. Students stated that "all lecturers need to have and show the sensitivity of cultural diversity as well as the need to cross the subject" [43].

Lecturers with less than ten years of teaching experience $(\mathrm{M}=2.781, \mathrm{SD}=.32)$ have a higher level of cultural diversity sensitivity than lecturers with more than ten years of teaching experience $(\mathrm{M}=2.775, \mathrm{SD}=.26)$. The findings show that lecturers with less than ten years of teaching experience have a higher cultural diversity level than lecturers with more than ten years of teaching experience. However, data analysis for the criteria of lecturers who have 
more than ten years of experience teaching lecturers of various ethnicities and cultures has a higher level of cultural diversity sensitivity than lecturers with less than ten years of experience teaching lecturers of multiple races and cultures. The findings of this study are in line with a study that confirms the assumptions found in DMIS, that is, "the more one's experience of cultural diversity, the higher one's ability to adapt to issues that exist between cultures" [44].

Lecturers who have experience teaching multi-ethnic and multicultural students More than ten years $(\mathrm{M}=2.78, \mathrm{SD}=.26)$ have a higher level of cultural diversity sensitivity compared to lecturers who have less than ten multi-ethnic and multicultural students' teaching experience years $(\mathrm{M}=2.77, \mathrm{SD}=.31)$. Lecturers who have attended a Cultural Diversity Course or Training have a higher cultural diversity level than lecturers who have never attended a Cultural Diversity Course or Training. The findings of this study are in line with a survey conducted on intercultural sensitivity among K-12 lecturers in the United States found that "intercultural sensitivity can be built through intercultural initiatives and professional development programs" [45].

This study is in line with the aspirations Indonesian Education goal which aims to produce lecturers sensitive to different student backgrounds and address racial relations positively and proactively. This study's findings give practical implications, especially to lecturers about the need for lecturers to prepare themselves to be a lecturer with a high level of cultural diversity sensitivity. The high level of cultural diversity sensitivity among lecturers will ensure that the teaching and learning process takes place effectively regardless of differences in students of various ethnicities and cultures. Support from higher education administrators, such as implementing programs that can increase cultural diversity sensitivity among lecturers at the higher education level, can help inculcate practices and increase cultural diversity sensitivity among lecturers. The needs to examine the aspects that need to be given attention to increasing cultural diversity sensitivity among lecturers, whether for lecturers in state or private higher education. It needs to design appropriate programs and courses to prepare lecturers to have a high cultural diversity sensitivity level. It is required to evaluate existing lecturer education programs to update and improve the lecturer education programs offered to produce a generation of educators with a high level of cultural diversity sensitivity. The teaching program should be exposed to the real situation regarding students' cultural diversity and not just based on theory alone.

This multicultural sensitivity study uses questionnaires adapted from several related studies that have been conducted abroad. Further research is needed to construct a questionnaire on cultural diversity sensitivity that is more relevant to the lecturers at Universitas Kristen Indonesia context. In this study, the data collection process only involved lecturer questionnaires. Future studies should add data collection methods such as interview methods. Observation and experimental approaches can also be carried out so that the researcher can control some external factors that can influence the study's findings. Further research should examine other aspects not studied in this study, such as the aspects contained in the sensitivity of cultural diversity. Further study should also involve moderation and mediator variables as well as independent and dependent variables.

\section{CONCLUSION}

This study was conducted in a higher education environment consisting of multi-ethnic students. The multi-ethnic higher education environment provides cultural diversity experiences for lecturers to learn, feel, and celebrate the cultural diversity that exists among students. This multi-ethnic higher education environment also provides space and opportunities for lecturers to practice cultural diversity sensitivity. This study has also clearly described the sensitivity of cultural diversity among lecturers based on ethnicity, gender, level of education, the field of teaching, teaching experience, teaching experience of students of various races and cultures, and courses or training of cultural diversity that lecturers have attended. Overall, based on the reading survey conducted by lecturers should have a high level of cultural diversity sensitivity to ensure the teaching and learning process runs smoothly in line with the reality of diverse backgrounds of students of various ethnicities and cultures. 


\section{REFERENCES}

[1] Jakupov, S. M., Perlenbetov, M. A., Ilimkhanova, L. S., \& Telebayev, G. T. (2012). Cultural values as an indicator of inter-ethnic harmony in multicultural societies. Procedia-Social and Behavioral Sciences, 69, 114-123.

[2] Zhang, Y., \& Buzan, B. (2012). The tributary system as the international society in theory and practice. The Chinese Journal of International Politics, 5(1), 3-36.

[3] Hodkinson, P., Biesta, G., \& James, D. (2008). Understanding learning culturally: Overcoming the dualism between social and individual views of learning. Vocations and learning, 1(1), 27-47.

[4] Tyas, E. H., \& Sunarto, L. N. (2020). Building Superior Human Resources through Character Education.

[5] Tuffin, K. (2008). Racist discourse in New Zealand and Australia: Reviewing the last 20 years. Social and Personality Psychology Compass, 2(2), 591-607.

[6] Quaye, S. J., Harper, S. R., \& Pendakur, S. L. (Eds.). (2019). Student engagement in higher education: Theoretical perspectives and practical approaches for diverse populations. Routledge.

[7] Cnyrim, A. (2016). Developing intercultural competence through authentic projects in the classroom. Authentic experiential learning in translator education, 129-145.

[8] Yuen, C. Y. (2010). Dimensions of diversity: Challenges to secondary school teachers with implications for intercultural teacher education. Teaching and Teacher Education, 26(3), 732-741.

[9] Sam, D. L., \& Berry, J. W. (2010). Acculturation: When individuals and groups of different cultural backgrounds meet. Perspectives on psychological science, 5(4), 472-481.

[10] Nieto, C., \& Zoller Booth, M. (2010). Cultural competence: Its influence on the teaching and learning of international students. Journal of Studies in International Education, 14(4), 406-425.

[11] Hue, M. T., \& Kennedy, K. J. (2012). Creation of culturally responsive classrooms: Teachers' conceptualization of a new rationale for cultural responsiveness and diversity management in Hong Kong secondary schools. Intercultural Education, 23(2), 119-132.

[12] DeJaeghere, J. G., \& Zhang, Y. (2008). Development of intercultural competence among US American teachers: Professional development factors that enhance competence. Intercultural education, 19(3), 255-268.

[13] Penbek, Ş., Yurdakul Şahin, D., \& Cerit, A. G. (2012). Intercultural communication competence: A study about university students' intercultural sensitivity based on their education and international experiences. International Journal of Logistics Systems and Management, 11(2), 232-252.

[14] Perry, L. B., \& Southwell, L. (2011). Developing intercultural understanding and skills: Models and approaches. Intercultural education, 22(6), 453-466.

[15] Yu, T., \& Chen, G. M. (2008). Intercultural sensitivity and conflict management styles in cross-cultural organizational situations.

[16] Naibaho, L. (2014). The Role of Education and Culture in the Development of Character and Civilization of the Plural Indonesian Nation. Jurnal the Ary Suta Center Series on Strategic Management, 27(0), 69.

[17] Chocce, J. (2014). Factors Favoring Intercultural Sensitivity. International journal of innvative research in information security, 1(6), 5-11.

[18] Schnabel, D. B., Kelava, A., Van de Vijver, F. J., \& Seifert, L. (2015). Examining psychometric properties, measurement invariance, and construct validity of a short version of the Test to Measure Intercultural Competence (TMIC-S) in Germany and 
Brazil. International Journal of Intercultural Relations, 49, 137-155.

[19] Bennett, M. J. (2017). The developmental model of intercultural sensitivity. The international encyclopedia of intercultural communication, 1-10.

[20] Na, J., Grossmann, I., Varnum, M. E., Kitayama, S., Gonzalez, R., \& Nisbett, R. E. (2010). Cultural differences are not always reducible to individual differences. Proceedings of the National Academy of Sciences, 107(14), 6192-6197.

[21] Morales, K., Henrquez, S. S., Carrillo, M. F., \& Bravo, P. R. (2017). The intercultural sensitivity of chilean teachers serving an immigrant population in schools. Journal of New Approaches in Educational Research (NAER Journal), 6(1), 71-77.

[22] Cushner, K. (2011). Intercultural research in teacher education: An essential intersection in the preparation of globally competent teachers. Action in Teacher Education, 33(56), 601-614.

[23] Prieto, L. R. (2012). Initial factor analysis and cross-validation of the Multicultural Teaching Competencies Inventory. Journal of Diversity in Higher Education, 5(1), 50.

[24] El Sayed, V., Teyssier, J., Denoux, P., \& Costa-Fernandez, E. (2020). Interculturation and Intercultural Sensitivity: Implementation of The Major Concepts for A Better Management of Cultural Otherness. Hellenic Journal of Psychology, 17, 139-158.

[25] Tyas, E. H., \& Naibaho, L. (2020). Building A Culture of Tolerance Since Early Childhood. International Journal of Research-GRANTHAALAYAH, 8(8), 244249.

[26] Diller, J. V. (2013). Cultural diversity: A primer for the human services. Nelson Education.

[27] Oscan, D., \& Amer, B. N. M. B. Development Intercultural Competence in English Language Learning Classroom.
[28] Wang, J. (2013). Moving towards ethnorelativism: A framework for measuring and meeting students' needs in cross-cultural business and technical communication. Journal of technical writing and communication, 43(2), 201-218.

[29] Tyas, E. H., \& Naibaho, L. (2020). A Harmony Among of Religious Community is Required Amidst the Covid-19 Pandemic. International Journal of Research-GRANTHAALAYAH, 8(9), 422428.

[30] Sadykova, G. (2014). Mediating knowledge through peer-to-peer interaction in a multicultural online learning environment: A case study of international students in the US. International Review of Research in Open and Distributed Learning, 15(3), 2449.

[31] Savicki, V. (Ed.). (2020). Developing intercultural competence and transformation: Theory, research, and application in international education. Stylus Publishing, LLC.

[32] Clarke III, I., Flaherty, T. B., Wright, N. D., \& McMillen, R. M. (2009). Student intercultural proficiency from study abroad programs. Journal of Marketing Education, 31(2), 173-181.

[33] Race, R. (2015). Multiculturalism and education. Bloomsbury Publishing.

[34] Holsapple, M. A. (2012). Service-learning and student diversity outcomes: Existing evidence and directions for future research. Michigan Journal of Community Service Learning, 18(2), 5-18.

[35] Naibaho, L., \& Ambrosia, Y. (2019). Students' Perception on Guessing Game Use in Learning Vocabulary at SMPK Ignatius Slamet Riyadi.

[36] Nadeak, B., \& Naibaho, L. (2018). The Description of medical students' interest and achievement on anatomy at faculty of medicine Universitas Kristen Indonesia. International Journal of 
Sciences: Basic and Applied Research (IJSBAR), 39(1), 121-133.

[37] Klak, T., \& Martin, P. (2003). Do university-sponsored international cultural events help students to appreciate "difference"?. International journal of intercultural relations, 27(4), 445-465.

[38] Miville, M. L., Gelso, C. J., Pannu, R., Liu, W., Touradji, P., Holloway, P., \& Fuertes, J. (1999). Appreciating similarities and valuing differences: The Miville-Guzman Universality-diversity scale. Journal of Counseling Psychology, 46(3), 291.

[39] Tyas, E. H., \& Naibaho, L. (2018). Leadership: Style And Its Role In Carrying Out The Mental Revolution.

[40] Çiloglan, F., \& Bardakçi, M. (2019). The Relationship between Intercultural Sensitivity and English Language Achievement. Journal of Language and Linguistic Studies, 15(3), 1204-1214.

[41] Naibaho, L. (2020). Female and Males' brain Tendencies in Learning English as a Second Language. International Journal of Research-GRANTHAALAYAH, 8(7), 211216.

[42] Küllü-Sülü, A. (2014). The role of native English speaking teachers in promoting intercultural sensitivity (Doctoral dissertation, Bilkent University).

[43] Gay, G. (2010). Acting on beliefs in teacher education for cultural diversity. Journal of teacher education, 61(1-2), 143-152.

[44] Cushner, K. (2007). The role of experience in the making of internationally-minded teachers. Teacher

Education

Quarterly, 34(1), 27-39.

[45] DeJaeghere, J. G., \& Cao, Y. (2009). Developing US teachers' intercultural competence: Does professional development matter?. International Journal of Intercultural Relations, 33(5), 437-447. 